Revista de Economia Política, vol. 31, $n^{\circ} 1$ (121), pp. 56-76, janeiro-março/2011

\title{
O mito do populismo econômico de Vargas
}

\author{
PEDRO CEZAR DUTRA FONSECA*
}

The myth of Vargas' economic populism. The Second Vargas Administration in Brazil (1951-1954) is commonly associated with the phenomenon of populism. However, based on the models of economic populism, it is clear that the economic policy of the period is not the one shown by those models. Besides, based on this historic experience, it is advocated that there is no incompatibility between developmentalism and the adoption of macroeconomic stability-oriented measures.

Keywords: Brazilian economy; Vargas; economic populism; developmentalism.

JEL Classification: N16; P48.

\section{DESENVOLVIMENTISMO E POPULISMO}

A relação entre desenvolvimentismo e populismo é tema recorrente entre economistas e demais cientistas sociais latino-americanos. Atualmente, retorna à ordem do dia com o novo-desenvolvimentismo e sua proposta de um projeto nacional de desenvolvimento sem, todavia, retornar ao "velho" desenvolvimentismo, o qual seria impregnado de práticas populistas. ${ }^{1}$ Esta diferenciação entre desenvolvimentismo e populismo constitui uma das premissas do novo-desenvolvimentismo, posto que se configura como reatualização, com nova forma, da "tese-síntese" da tradição cepalina, segundo a qual o desenvolvimento dos países latino-americanos não brotaria espontaneamente do livre jogo das forças de mercado, mas precisava ser induzido. A discordância atual centra-se em seus meios e instrumentos, como protecionismo, reservas de

\footnotetext{
* Professor titular do Departamento de Ciências Econômicas da Universidade Federal do Rio Grande do Sul - UFRGS e pesquisador do CNPq. Agradeço os comentários prévios de Sérgio M. Monteiro e ao bolsista de Iniciação Científica/PIBIC Diego Mambrin. E-mail: pedro.fonseca@ufrgs.br. Submetido: Setembro 2009; Aprovado: Novembro 2009.

${ }^{1}$ Sobre o novo-desenvolvimentismo, ver: Bresser-Pereira (2003, cap. 20; 2004; 2006; 2006b); Sicsú et al. $(2005$; 2007) e Cunha \& Ferrari (2009).
} 
mercado, valorização cambial e déficits crônicos - não propriamente defendidos por teóricos da envergadura de Prebisch e Furtado - mas que efetivamente teriam sido praticados por governos "populistas". Em resumo: o novo-desenvolvimentismo defende a retomada de um projeto nacional de desenvolvimento, mas depurado do populismo. Esta diferenciação nunca foi aceita pela ortodoxia convencional latino-americana, para quem a indissociabilidade entre desenvolvimentismo e populismo constitui tradicional recurso para desqualificar as políticas intervencionistas pró-crescimento, tanto as do antigo estruturalismo cepalino como as keynesianas e, agora, as sugeridas pelo novo-desenvolvimentismo. Como é por demais conhecido, a ortodoxia sempre considerou, e principalmente a partir de Solow, o crescimento econômico como variável endógena, tornando desnecessárias medidas indutoras, a não ser as voltadas a garantir o pleno funcionamento dos mercados ou com atuação restrita a contra-arrestar suas eventuais falhas.

Embora o termo populismo esteja sujeito a múltiplas definições e empregado por diferentes autores para designar fenômenos históricos de ampla diversidade, admite-se aqui o corte teórico entre populismo político e populismo econômico, consagrado na literatura das últimas duas décadas. ${ }^{2}$ Em princípio, ambos têm comum a carga sempre depreciativa associada a governos tidos como "demagógicos", "irresponsáveis" ou "manipuladores" de conflitos; todavia, para fins analíticos, e mesmo com recorrência a certo grau de abstração, podem ser pensados e tipificados separadamente, já que passíveis de ocorrerem separadamente. O objeto deste artigo é a política econômica do Segundo Governo Vargas - SGV (1951-54). A escolha deste período possui razões muito precisas. Vargas é tradicionalmente considerado (junto com Goulart, seu "sucessor") o exemplo mais típico do populismo brasileiro, colocado ao lado de latino-americanos como Cárdenas (México, 1934-40), Perón (Argentina, 1946-45), Allende (Chile, 1971-73) e Alan Garcia (Peru, 1985-88), dentre outros. ${ }^{3}$ Apesar de ter governado o Brasil por praticamente duas décadas, seu segundo governo é sempre o mais lembrado para exemplificar o populismo, posto que marcado por episódios simbólicos de vulto, como a campanha da Petrobras, a criação do BNDE, a greve dos "300 mil”, a ascensão de João Goulart como Ministro do Trabalho e sua demissão, por pressão do "Manifesto dos Coroneis", sem contar a radicalização política cujo desfecho foi seu suicídio.

Deve-se a Bresser-Pereira (1991, p. 8), ao comparar populismo econômico e político, a afirmação, em direção oposta à da literatura, que Vargas "jamais adotou o populismo econômico”. Por seu caráter polêmico, entendeu-se merecer uma mais detalhada verificação empírica. Assim, incorpora-se esta asserti-

\footnotetext{
${ }^{2}$ Parte desses artigos encontra-se publicado em Bresser-Pereira (1991), de onde foram extraídas as citações a seguir. Nas referências bibliográficas, a edição original aparece com o ano entre colchetes.

${ }^{3}$ Ver, p.e.: Sachs ([1989] 1991, p. 133) e Masiero, in Bresser-Pereira (1991, p. 240).
} 
va neste trabalho ao se formular a hipótese de que a política econômica do SGV se afasta do denominado populismo econômico, mesmo em se tratando de governo com compromissos explícitos com um projeto de longo prazo consagrado na literatura como "desenvolvimentismo" ou "nacional-desenvolvimentismo". Como corolário, pretende-se também contribuir, em caráter exploratório, para reafirmar a premissa do novo-desenvolvimentismo, antes mencionada, sobre a inexistência de relação unívoca ou necessária entre desenvolvimentismo e populismo. Frente a multiplicidades de usos em que estes termos são empregados, cabe precisá-los. Recorrendo a Bielschowsky (1988, p. 7), o desenvolvimentismo pode ser definido como a "ideologia de transformação da sociedade brasileira" assentada em um projeto econômico voltado à industrialização como via de superação da pobreza e do subdesenvolvimento, sob o entendimento de que esta não adviria pela espontaneidade das forças de mercado, ou seja, seria indispensável a atuação do Estado como indutor, agente planejador do desenvolvimento e/ou investidor direto. $\mathrm{Na}$ mesma direção, em outro trabalho (Fonseca, 2004, p. 226), mostrou-se que embora a definição de desenvolvimentismo varie entre autores, há um "núcleo duro" para o qual estes convergem, constituído pela defesa: (a) da industrialização; (b) do intervencionismo pró-crescimento; e (c) do nacionalismo, embora este deva ser entendido num sentido muito amplo, que vai desde a simples retórica ufanista conservadora até propostas radicais de rompimento unilateral com o capital estrangeiro.

A desconstrução da tese que associa Vargas ao populismo político ganhou impulso inicial com o trabalho de historiadores como Gomes ([1988] 2005), Bodea (1992) e, mais recentemente e de forma enfática, com Ferreira (1997, 2005). ${ }^{4}$ Estes mostram a impropriedade de reduzir o complexo fenômeno do trabalhismo brasileiro a elementos como "manipulação das massas" por líder "demagógico e carismático", embora "autoritário", que se "aproveita” do "baixo nível de consciência" para lhe fazer "concessões" e, com isso, impedir o avanço da "marcha histórica" em direção ao socialismo. Bresser-Pereira (2007, pp. 72-73), por sua vez, mesmo mantendo a categoria de análise, elabora nítida distinção entre populismo econômico e político e, ao contrário da literatura tradicional, substitui a interpretação depreciativa por outra, a qual o resgata como fenômeno histórico: para uma sociedade de formação oligárquica e que dava os primeiros passos rumo à democratização, à industrialização e à urbanização, "o populismo político é um avanço em relação ao passado autoritário porque é uma forma inicial de participação popular, é uma manifestação da democracia que está emergindo". Este não se confundiria

\footnotetext{
${ }^{4}$ As reflexões teóricas mais instigantes sobre populismo político devem-se a Gino Germani, Torcuato di Tella e Ernesto Laclau. Registram-se as contribuições de Francisco Weffort, Fernando Henrique Cardoso e Octavio Ianni dentre as de maior envergadura na utilização do conceito para caracterizar a história política brasileira entre 1930 e 1964. Sobre o uso do termo populismo no Brasil, veja os artigos de Gomes e Ferreira em Ferreira (2001).
} 
com o populismo econômico, "mais simples e direto: ocorre quando o governo, para agradar os eleitores, gasta mais do que arrecada". Este artigo pretende somar-se a este esforço intelectual, embora enfoque primordialmente variáveis de natureza econômica. Se seu objetivo e hipótese são de simples formulação, o maior desafio enfrentado foi metodológico: como testar se um governo afina-se ou não com o populismo econômico? Que caminho seguir para evitar tão simplesmente a sucessão de juízos de valor explícitos ou, o que não é muito diferente, o recurso contumaz da ortodoxia, de "julgar" a política econômica (se "coerente", "consistente" e, inclusive "populista") a partir do próprio modelo que formula, caso, não raramente, em que a conclusão está embutida nas próprias premissas? A opção recaiu em partir da literatura e dela extrair o que seus principais autores consideram como populismo econômico para, com estes elementos em mão, ter-se condições de selecionar e investigar algumas variáveis relevantes da política econômica do período histórico em pauta para testá-la empiricamente. Não se pretende, hit et nunc, questionar o conceito ou seu uso, tampouco contrapor as diversas acepções e nuanças assumidas pelo mesmo, mas tão somente identificar o hard core deste programa de pesquisa como caminho para se analisar a política econômica do SGV e verificar-se a pertinência da utilização, tão generalizada, para assim qualificá-la e arrolá-la como um dos casos "típicos".

\section{POPULISMO ECONÔMICO}

Os modelos sobre populismo econômico geralmente assentam-se em construções teóricas voltadas a caracterizar um padrão de política econômica que se expressa através de ciclos. Os diversos modelos não diferem substancialmente. Embora enfatizem instrumentos diferentes, todos convergem (sob o suposto, explícito ou não, de uma curva de Philips a curto prazo negativamente inclinada) em afirmar que o fenômeno associa-se a um padrão de comportamento cuja marca é crescer aceleradamente, mesmo em situações adversas, ignorando ou subestimando políticas de estabilização. Ao assumirem diante de uma conjuntura adversa, os governos populistas acusam seus antecessores de responsáveis por recessão e desemprego, negam-se a reconhecer a necessidade de medidas restritivas e propõem uma "virada" drástica da política econômica, apresentando, como alternativa, maior crescimento.

Os primeiros artigos que procuraram definir populismo econômico como um fenômeno com lógica própria, de modo a tornar-se objeto de análise, partiram da experiência argentina. ${ }^{5}$ Assim, Canitrot ([1975] 1991), embora não chegue à identificação de um ciclo, enfatiza a política salarial como o instru-

\footnotetext{
${ }^{5}$ Para um trabalho mais recente que analisa em profundidade a política econômica de Perón, veja Ferrari (2007).
} 
mento por excelência dos governos populistas: seus líderes encontram campo fértil em períodos recessivos e prometem crescimento, distribuição de renda e empregos. Após eleitos, optam por aumentos generosos de salários como forma de viabilizar seu programa, o que se transforma em seu gargalo, com a aceleração da inflação: o artigo defende a impossibilidade de redistribuir renda a favor dos salários e contra os lucros numa economia aberta e com mobilidade de capital (p. 13), e que "o gasto público é um meio mais eficiente de redistribuição de renda que o aumento de salários” (p. 15). Já com O’Donnell ([1977]1991) aparece embrionariamente a noção de ciclos, ao elaborar um modelo de economia dual, com um setor exportador relativamente autônomo ao lado de outro, voltado para dentro, com produção de bens-salário ou não-comercializáveis. Embora não utilize a palavra populismo, mostra como o equilíbrio instável advindo da dualidade resulta em alianças políticas temporárias, de difícil sustentação a longo prazo, as quais alternadamente priorizam um setor e outro, ocasionando um movimento "pendular" (p. 61). O terceiro artigo, de Díaz-Alejandro ([1981]1991), já propõe uma versão mais acabada de ciclo econômico populista. A partir da análise de diversos planos frustrados de estabilização, mostra que estes evidenciam um padrão repetitivo de sequência de fases, o qual sempre começa com opção pelo crescimento e por rejeição a políticas restritivas para combater a inflação. Segue-se, então, um período inicial de euforia, mas fugaz, pois logo as consequências nefastas aparecem: déficit público, desequilíbrio no balanço de pagamentos, mais inflação - a exigir um ajuste ainda mais drástico do que o inicial, "cujos custos suscitam a questão sobre se não será pior a cura do que a própria doença” (p. 75). Normalmente, registra, os governos populistas não admitem seu equívoco e atribuem o fracasso a forças políticas ou econômicas reacionárias, internas ou externas.

Com vistas a analisar posteriormente a política econômica do SGV, retoma-se sinteticamente a visão de ciclo econômico populista de seus principais formuladores:

a) Díaz-Alejandro ([1981]1991): o ciclo apresenta as seguintes fases: (a) expansão geral de salários e gastos públicos não financiados por aumento de impostos, seja por ser impopular ou simplesmente por ser considerado dispensável, ante a necessidade de "reformas estruturais"; (b) o déficit é financiado preferencialmente por emissão monetária; (c) o aumento nos gastos é mais canalizado para consumo do que para investimento; (d) nestas fases iniciais, crescem a produção, especialmente dos bens-salário, e as importações; estas são financiadas por queima de reservas e/ou por empréstimos externos; (e) gradualmente a inflação aparece, mas o governo nega-se a desacelerar a demanda, sob o entendimento de "que os preços não devem subir, apenas os salários" (expressão de McKinnon, in Bresser-Pereira, 1991, p. 99); normalmente a opção é por controle de preços e por evitar a desvalorização cambial; (f) o déficit público torna-se insustentável, as contas do 
balanço de pagamento estouram, a inflação dispara e o crescimento cessa; e (g) a euforia cede espaço ao desânimo e ao acirramento dos conflitos políticos. Abre-se espaço para políticas ortodoxas radicais, muitas vezes implementadas por manu militari (p. 79);

b) Sachs ([1989]1991): elabora uma versão semelhante à de O’Donnell, com dois setores, um exportador de bens primários e outro produtor de bens não comercializáveis, trabalho intensivo e dependente de insumos importados; a taxa de câmbio é a variável por excelência para arbitrar ganhos e perdas entre os setores. O "populismo cambial" manifesta-se no seguinte ciclo: (a) valorização inicial do câmbio, a qual pode ser alcançada com a adoção de taxa nominal fixa associada à expansão monetária; (b) os saldos monetários reais aumentam, diminui a taxa de juros e eleva a demanda agregada; (c) a demanda por trabalho no setor de não comercializáveis cresce, assim como o emprego e o poder de compra dos salários, este definido como a razão entre os salários nominais e os preços dos bens de consumo; (d) como cai relativamente o preço dos bens exportáveis, contraem-se a produção do setor exportador e as exportações, enquanto a demanda por insumos importados cresce; (e) a crise do balanço de pagamentos denuncia a incongruência das medidas, constituindo-se no grande gargalo do populismo cambial: a euforia inicial acaba e abre-se para a crise (p. 131);

c) Dornbusch e Edwards ([1989] 1991; 1990): assinalam que os programas populistas geralmente partem de uma situação de economia estagnada ou em depressão, a qual cria condições para programas fortemente expansionistas; a "retomada com distribuição" é a palavra de ordem. Seguem-se quatro fases: (a) aumentos salariais e políticas de aquecimento da demanda, atendida por importações, diminuição de estoques e/ou suspensão de pagamentos ao exterior, num primeiro momento ainda com inflação baixa; (b) pontos de estrangulamento aparecem gradualmente e o governo rejeita medidas estabilizadoras, optando por controle cambial ou protecionismo: (c) a crise se aprofunda, há fugas de capitais, desmonetização, cai a arrecadação e o déficit público se deteriora; com a inflação ascendente, os salários reais caem e a situação política instabiliza-se; (d) abre-se espaço para a adoção de políticas de cunho ortodoxo (p. 154);

d) Bresser-Pereira (1989): sua formulação é mais abrangente do que as anteriores em pelo menos três aspectos: (1) mostra diferentes possibilidades para começo do ciclo, apontando para a diversificada gama de experiências; (2) difere o populismo econômico "de esquerda", assentado no "distributivismo ingênuo via salários e com a recusa de ajustamento", do "de direita", cuja preferência recai no gasto público e no clientelismo (p. 111); e (3) ao considerar a política econômica de ou- 
tros países latino-americanos, dá ênfase à experiência brasileira, aspecto particularmente importante para o objetivo deste artigo. Assim: (a) a primeira fase caracteriza-se por forte crescimento e inflação baixa, e pode ser desencadeada por várias alternativas, não excludentes, a partir de um conjunto de um conjunto de medidas como: (i) valorização cambial, com o decorrente crescimento das importações, dos salários e do consumo doméstico; (ii) aumentos salariais, seja do setor público ou do setor privado; (iii) elevação das despesas e do déficit público; (iv) taxa de juros artificialmente baixa; e (v) represamento de preços e tarifas públicas. Ao configurar o ciclo, uma combinação destas medidas inicialmente induz o crescimento dos salários e das demanda de consumo e de investimento; (b) após o "paraíso momentâneo", agrava-se a crise do balanço de pagamentos e o descontrole do déficit público leva a uma crise fiscal; (c) a desvalorização cambial torna-se inevitável, a inflação dispara e a crise econômica e política se aprofunda, finalizando com "mudanças dos ministros responsáveis, se não por um golpe de Estado” (p. 111).

Pode-se constatar que os modelos, a despeito das diferenças de nuanças, convergem ao assinalar medidas cuja repetição sugere fazerem parte do hard core do populismo econômico: (a) política salarial frouxa, com ganhos superiores à produtividade (o chamado "populismo salarial"); (b) aumento de gastos públicos não coberto por impostos ("populismo fiscal”); (c) apreciação do câmbio ("populismo cambial”). A relevância deste último vem sendo enfatizada por autores como Bresser-Pereira (2006), inclusive em trabalho com Nakano (2003) e com Gala (2007). Estes destacam a interrelação entre a taxa cambial e as demais variáveis, como salariais e fiscais, de forma a comprometer o crescimento de longo prazo, devido seu impacto na poupança interna: "déficits em conta-corrente são compatíveis com taxas de câmbio apreciadas, que aumentam artificialmente os salários e o consumo, e diminuem a poupança interna, de forma que, em situações normais, em que a taxa de lucro esperada não é especialmente elevada, o influxo de poupança externa implica elevada substituição de poupança interna por externa" (2006, p. 20). Assim, a entrada de capital estrangeiro pouco contribui para o crescimento, embora aumente a dívida externa e o comprometimento futuro de remessas de lucros e juros; o aumento "artificial" do consumo presente transfere seu custo, comprometendo o crescimento de longo prazo. Nakano (2007, p. 12) compartilha desta visão de enfatizar o chamado populismo cambial e seu impacto nas demais variáveis: o limite do ciclo populista se encerra quando esbarra no superávit em transações correntes, "pois ampliar exportações e reduzir importações só será possível com a redução do consumo doméstico".

Finalmente, salta aos olhos que todos os autores registram como fase inicial de seus modelos medidas expansionistas, muitas vezes drásticas, acom- 
panhadas de rejeição a políticas de estabilização. Pode-se claramente concluir que é nesta primeira fase que o populismo econômico se revela, na convicção do governo de que pode enfrentar a situação com a referida "virada" pró-crescimento acelerado e acompanhado de distribuição de renda, ao invés de optar por políticas restritivas. Como construção lógica, esta primeira fase é variável-chave dos modelos, já que os mesmos ilustram, através do encadeamento de variáveis, cada fase como decorrente da anterior; as medidas da primeira fase evidenciam o que o governo quer elou pensa e, em adição, constituem o gérmen do desfecho sempre perverso. Do ponto de vista metodológico, isto sugere que o teste empírico relativo a uma dada conjuntura histórica, como aqui se propõe, deva partir não apenas de dados ex-post, mas também de outros materiais de pesquisa, como discursos e pronunciamentos das autoridades e policymakers, capazes de contribuir para se detectar a intenção dos governantes, ou pelo menos mostrar se compartilham dessa convicção. Em síntese: populismo econômico, para todos os autores, é sobretudo um padrão de comportamento, muitas vezes culturalmente arraigado — ou "embedded", como na tradição institucionalista — o qual, sob determinadas condições políticas permissivas, manifesta-se na formulação da política econômica. A América Latina seria seu palco por excelência. O SGV seria um caso a exemplificá-lo?

Comecemos com uma descrição, mesmo breve, da política econômica do primeiro ano do SGV com o fito de perscrutar se nela há elementos suficientes para corroborar as fases e as políticas constantes dos modelos.

\section{O SGV E O “TESTE” DA FASE INICIAL}

Quando Vargas retornou ao poder, no início de 1951, a conjuntura econômica apresentava um quadro de dificuldades crescentes. A inflação, medida pelo Índice de Preços ao Consumidor do Rio de Janeiro (IBGE), praticamente triplicara em dois anos, indo de 3,45\% para 9,40\% de 1948 para 1950 . A aceleração surpreendia dentre outros motivos porque o governo anterior, do presidente Dutra, havia tomado pelo menos duas medidas que serviam de âncora anti-inflacionária: o congelamento do salário mínimo, cujo último reajuste ocorrera em 1943, pelo próprio Vargas, e a fixação do câmbio, com a consequente valorização real do cruzeiro. Dificilmente esta última medida pode ser interpretada com um sintoma de populismo de Dutra, não só por se tratar de governo conservador, como bem mostra a política salarial, como por esta decisão vincular-se fundamentalmente ao acordo de Bretton Woods. O impasse entre o cumprimento deste e o agravamento da situação do balanço de pagamentos fora herdado por Vargas, e o problema aguçava-se com o passar do tempo, diante do processo inflacionário. A Tabela 1 ilustra o problema apenas 
em parte, porquanto a simples leitura do balanço de pagamentos subestima a gravidade do quadro: parte das divisas acumuladas, principalmente durante a Segunda Guerra, dera-se com moedas tornadas inconversíveis a partir com o referido acordo, que estabeleceu o dólar como moeda por excelência das transações internacionais. Em fevereiro de 1948, depois de uma fase mais liberalizante, o governo Dutra adotou o sistema de "contingenciamento das importações", pelo qual administrava a escassez de divisas através de "licenças prévias" às importações, as quais eram concedidas de acordo com a "essencialidade" dos bens". Começava com Dutra uma forma "política" de administração da escassez de divisas: mantinha-se a taxa cambial fixa e se preservava os interesses desenvolvimentistas, posto que as primeiras faixas reservavam-se a bens de capital e insumos básicos necessários à produção industrial e agrícola (Saretta, 2000, p. 89; Bastos, 2004).

$\mathrm{Na}$ campanha presidencial, o candidato Vargas, mesmo em lugares mais distantes e sem público propenso à identificação fácil com a proposta, reafirmava em cada oportunidade seu desejo de retornar ao poder para dar continuidade a seu projeto de industrializar o país e modernizá-lo, abrangendo nesta última expressão também a diversificação do setor primário (Fonseca, 1989, p. 347). Em consonância ao que mais tarde denominar-se-ia "nacional-desenvolvimentismo", acenava para a necessidade de avanço para os bens de capital e intermediários. Ao assumir a Presidência, deparou-se com o quadro adverso. Além da deterioração gradual do câmbio, agravada pela retração do comércio internacional com a Guerra da Coreia, e da inflação crescente, a execução orçamentária da União em 1950 apresentou déficit nominal de Cr\$ 4.297 milhões, com receitas de Cr\$19.372 milhões e despesas de Cr\$23.669 (IBGE, 1987, p. 571). Por outro lado, as demandas salariais cresciam e o descongelamento do salário mínimo parecia inadiável diante da pressão sindical e dos políticos aliados do governo. A conjuntura trazia à liça o clássico dilema entre estabilização e crescimento.

Vargas formara equipe predominantemente afinada com as teses desenvolvimentistas, com Horácio Lafer na Fazenda e Ricardo Jafet no Banco do Brasil. Em adição, inovou ao montar uma Assessoria Econômica ligada diretamente à Presidência destinada a pensar o longo prazo e atuar em projetos especiais, composta por homens tidos como "nacionalistas", chefiada por Rômulo de Almeida e da qual participavam, dentre outros, Ignacio Rangel, Jesus Soares Pereira, João Neiva de Figueiredo, Tomás Pompeu Borges e Cleanto de Paiva Leite. Os compromissos da equipe com as teses desenvolvimentistas, todavia, não impediu que houvesse consciência da gravidade do quadro e que o governo passasse a defender medidas de estabilização, como combate à inflação e ao déficit público. $\mathrm{O}$ discurso presidencial continuava a defender o projeto de desenvolvimento, mas alertava que não se poderia ignorar as adversidades "herdadas" (no que já criticava Dutra), com o risco de, ao agravar-se 
as finanças internas e o desequilíbrio externo, comprometer-se a própria execução do programa de crescimento. Detecta-se nesta postura de Vargas certa sofisticação que a impede de encaixá-la em interpretações polares e pré-moldadas. A rigor a proposta de buscar uma conciliação entre crescimento e estabilidade afasta-se da ortodoxia convencional e é argumento típico da heterodoxia teórica; à época, afinava-se perfeitamente com as teses da CEPAL. ${ }^{6}$ Entretanto, mostra claramente que não havia uma associação estreita entre desenvolvimentismo e rejeição $a$ priori à estabilidade, como faz crer a tradição ortodoxa, com o afã de considerá-lo "populista". Não se trata, também, de "mera retórica" para encobrir a "verdadeira natureza" do governo, seja ortodoxa ou desenvolvimentista. Para ir além desta simplificação: o material pesquisado desta quadra histórica sugere não existir incompatibilidade entre um governo afinado com o desenvolvimentismo, em certas conjunturas e diante de determinadas circunstâncias, optar por políticas de estabilização austeras ou contracionistas. Esta proposição fere quem costuma perceber a história como um exercício de lógica abstrata, ou a reduz a laboratório para testar a coerência ou racionalidade dos policymakers.

O ministro Lafer, então, passou a defender que temporariamente se deveria diminuir o ritmo do crescimento para enfrentar a inflação e o desequilíbrio do balanço de pagamentos - ao que tudo indica, com aval do próprio Vargas. Reafirmava que o programa de desenvolvimento continuava em pé, mas reconhecia a necessidade de medidas estabilizadoras. Como metáfora para ilustrar a decisão, passou a defender a "fórmula" Campos Salles - Rodrigues Alves —, pela qual deveria haver inicialmente uma fase de prioridade à estabilidade, como no governo do primeiro, para após se partir para o crescimento acelerado, como no período de Rodrigues Alves. Consta que a sugestão da "fórmula" fora de Osvaldo Aranha e se discute até hoje qual teria sido seu exato sentido: mera metáfora ou proposição de fato a ser seguida? Significava suspender de fato os projetos desenvolvimentistas ou tentar compatibilizá-los com medidas recessivas a curto prazo?

Tudo sugere que não se tratava de mera retórica, como defende parte da literatura, mas tampouco significava o abandono dos referidos projetos. Havia certa convicção de que a crise seria temporária e, com instrumentos adequados, poder-se-ia debelá-la. Certo otimismo decorria da recuperação, desde 1949, dos preços internacionais do café. Por outro lado, com mediação do

\footnotetext{
${ }^{6}$ Fonseca, 1989, p. 379. No pensamento de Vargas, pelo menos a partir da década de 1930, sempre se detecta a inquietação quanto à possibilidade de compatibilizar crescimento econômico com inflação, o que não significa que propusesse déficits crônicos, "irresponsáveis" ou "populistas". Nas palavras de Bastos (2009, p. 19): "O combate à inflação deveria ser realizado em duas frentes, simultâneas e complementares: ampliar a produção com apoio decidido das políticas cambial e de crédito, e assegurar equilibrio orçamentário".
} 
próprio Aranha, respeitado pelo governo norte-americano por seu papel destacado na ONU, em junho de 1951 foi instalada a Comissão Mista Brasil Estados Unidos, com o fito de estabelecer um diagnóstico da economia brasileira e propor projetos de desenvolvimento, os quais seriam financiados pelo BIRD e pelo EXIMBANK, num montante esperado de US\$ 300 milhões. Esta aproximação de Vargas com os Estados Unidos - a qual já se verificara durante a Segunda Guerra, com o pragmatismo muito lembrado por críticos e analistas e que contribuiu para a obtenção de financiamento e tecnologia para a implantação da indústria siderúrgica da época do Estado Novo - vem corroborar, nesta conjuntura de seu segundo governo, o fato de que o mesmo se afasta do protótipo de populismo econômico dos modelos antes mencionados. Estes normalmente são associados à valorização real do câmbio, mas neste período tudo sugere que as autoridades econômicas avaliaram que o custo de romper com o pactuado em Bretton Woods poderia ser maior. A taxa cambial fixa certamente colaborava para o programa de combate à inflação, mas dificilmente sua adoção decorria das motivações arroladas pelos modelos de populismo econômico, sem contar que provinha do governo anterior, a configurar uma continuidade e não uma "virada", como os modelos propõem. De fato, aproximar-se da política dos Estados Unidos no plano internacional e reconhecer a necessidade de estabilização fere o cerne do que poderia se esperar de governos "populistas" na América Latina, em sua fase inicial. Sua aposta primeira teria sido mais de uma política de boa vizinhança com vistas a obter o financiamento dos projetos, cujo ingresso de capitais daria certa folga ao balanço de pagamentos, em vez de qualquer atitude intempestiva.

Finalmente, cabe assinalar o afastamento do hard core dos modelos tanto na área salarial e como na fiscal no ano de 1951, passo metodológico decisivo para corroborar a hipótese de que a política econômica do SGV difere em aspectos estruturantes das medidas previstas pelos modelos de ciclo econômico populista.

Quanto à primeira: a despeito de toda a pressão sindical e das promessas de campanha, o governo resistiu e não reajustou o salário mínimo ao longo do ano, mantendo-o no mesmo nível de 1943. Aumentos salariais "irresponsáveis" em todos os modelos integram a fase inicial do ciclo, de forma que é praticamente impossível detectar-se o referido "padrão de comportamento" diante de sua ausência. Se é costumeiro o discurso oficial ocultar ou revelar apenas parte dos atos governamentais, neste caso registra-se bastante coerência entre ele e as medidas restritivas adotadas. Ilustra-o a Mensagem Presidencial enviada ao Congresso Nacional na abertura do ano legislativo de 1951, em que a defesa reiterada, em várias passagens, de um projeto de longo prazo assentado na industrialização e na distribuição de renda - v.g., o nacional-desenvolvimentismo - aparece lado a lado com justificativas da necessidade de implantar medidas amargas a curto prazo. Afirma que, por ora, tinha-se "pou- 
co a dividir", com o fito de prevenir que "uma distribuição insensata venha prejudicar o potencial de capitalização necessário ao desenvolvimento econômico geral e, assim, à criação de maiores e mais amplas oportunidades de emprego e salários". Esta manifestação vai na direção oposta do que os modelos consideram "populismo salarial" e escancara sua intenção, consciente, em sentido contrário. Nota-se que subjacente a ela está o entendimento de a produtividade deveria constituir limite ao crescimento dos salários não apenas devido aos dilemas macroeconômicos da conjuntura, pois permite a leitura desta regra como mais duradoura, já que poderia "prejudicar o potencial de capitalização necessário ao desenvolvimento". ${ }^{7}$ Ato politicamente corajoso tanto por alardear - e não encobrir - o que parte de sua base de sustentação partidária e sindical esperava, mas também por contrariar doutrina largamente difundida nos círculos trabalhistas sobre a função positiva entre os níveis de emprego e de salário, no entendimento de que este incrementaria a demanda (e, sobretudo, por justificar a própria legislação social, sempre capitalizada por Vargas como sua maior obra).

Quanto à área fiscal, a mesma Mensagem responsabiliza o governo Dutra pela "emissão de moeda irresponsável" e pelo déficit público, cuja solução exigia "medidas rigorosas de compressão de despesas" e aumento de arrecadação. Vários outros pronunciamentos presidenciais de 1951 seguem a mesma linha (Vargas, 1952, p. 140; 1950). Também a austeridade não restringiu ao discurso: no ano de 1951 registra-se queda de $3 \%$ do investimento público e retração expressiva da participação governamental na formação bruta de capital fixo, de $28,4 \%$ para $20,3 \%$ do PIB no mesmo período. A meta de superávit orçamentário foi viabilizada com crescimento real da receita da União entre 1950 e 1951, de Cr\$19,37 pra Cr\$23,17 bilhões, enquanto as despesas caiam de Cr\$23,67 para Cr\$20,78 bilhões, em valores de $1950 .{ }^{8}$ Como consequência, houve desaceleração no ritmo de crescimento do PIB em 1951 com relação a 1950 , com taxa de $4,9 \%$, a qual contrasta com os $9,7 \%$ e $7,7 \%$ do biênio 1948-49 e, principalmente, com a queda do crescimento do produto industrial para $5,3 \%$, quando atingira $11-12 \%$ nos últimos anos do governo Dutra (Abreu, 1989, pp. 398-403; ver também Tabela 1).

\footnotetext{
${ }^{7}$ Getulio Vargas, 1952, v. 1, p. 73. Mesmo durante o Estado Novo, em plena campanha voltada a divulgar a medida governamental de introdução do salário mínimo, ao lado de entendê-lo como "uma imposição da justiça social", afirmava "tratar-se de um mínimo de remuneração, dentro de um critério moderado e equitativo, capaz de evitar aos empregadores exigências incompatíveis com a nossa economia, sob muitos aspectos ainda incipiente e em fase de organização", e que o padrão de vida da população deveria crescer gradualmente, "aumentando, no decorrer do tempo, [com os] os índices de saúde e produtividade” (Vargas: 1938, v. 5, p. 172; 1944, v. 6, p. 205). Associar pronunciamentos como este a "demagogia" e "manipulação de massas" de caráter populista certamente constitui uma empreitada difícil.
}

${ }^{8}$ IBGE, 1987, p. 571. Os dados foram deflacionados pelo deflator implícito do PIB. 
Destarte, a análise, com todo o rigor e precaução, de quaisquer das políticas constantes do hard core antes mencionado para o ano de 1951, permite concluir que não há evidências de que o SGV possa ilustrar o previsto pelos modelos de ciclo econômico populista. Ao contrário, as políticas implantadas não só mostram consistência entre si como apontam para o oposto do previsto pelos respectivos modelos, além de serem justificadas nos discursos das autoridades. Inclusive, registra-se o fato frontalmente contrário ao enunciado nos modelos: Vargas acusa seu antecessor como responsável pelo déficit público - comportamento inesperado para um "populista". Há quem considere que esta coexistência da defesa de um projeto desenvolvimentista com a consciência da necessidade do combate à inflação e do controle dos déficits público e do balanço de pagamentos seria uma "contradição do populismo", ou simplesmente uma demonstração de seu conservadorismo e ortodoxia. ${ }^{9}$ Mas por que não admitir simplesmente que o governo, embora se mostrasse adepto das teses desenvolvimentistas, simplesmente não era "populista" — pelo menos da forma como os economistas o definem? A contradição seria do governo ou de seus intérpretes? Nada assegura que os dois conceitos tenham de ser a priori indissociáveis, tanto lógica como historicamente.

\section{OS ANOS SEGUINTES}

Se resta claro o contraste entre a política econômica até aqui analisada, referente ao ano de 1951, e a preconizada pelos modelos, cabe indagar sobre a dos nos anos seguintes, embora se reafirme que a análise do primeiro ano já seria suficiente para evidenciar que a mesma não se enquadra no previsto em qualquer formulação de ciclo econômico populista. Mostrar-se-á que esta prioridade nem sempre foi mantida, inclusive em decorrência de pressões políticas internas, mas não significa que o governo tenha de vez ignorado a necessidade de estabilização ou, num rompante "populista" tenha dado uma "virada". ${ }^{10}$ A opção mais forte pela estabilidade perdurou com toda a intensi-

\footnotetext{
${ }^{9}$ São os casos de Lessa \& Fiori, 1984; e Vianna, 1987, p. 120. Este surpreende com a interpretação de que Vargas teria uma "visão ortodoxa em assuntos de economia. Desde a época em que geriu o Ministério da Fazenda de Washington Luís até sua morte, as convicções do pensamento econômico ortodoxo foram as suas". Na verdade, estas "conviç̧ões" só se fizeram presente no pensamento de Vargas na Primeira República, quando adepto do positivismo, mas começaram a ser abandonadas já em 1928, ao assumir a Presidência do Rio Grande do Sul (Fonseca, 2004, p. 225-56). Críticas a estas afirmações serão retomadas na parte final deste trabalho.

${ }^{10}$ Um autor que defende a tese da "virada" é Skidmore, 1976, pp. 119-37. Mas, ao contrário dos ciclos populistas, esta teria ocorrido em meados do governo. Vários autores, posteriormente, criticaram essa interpretação, mostrando que tal dicotomia não se sustenta, tanto do ponto de vista político como da condução da política econômica: D’Araújo, 1982, p. 131-2; Lessa \& Fiori, 1984, p. 593; Vianna, 1987, p. 125; e Fonseca, 1989: 359. Em outro artigo (Fonseca \& Monteiro, p. 2005), com utilização
} 
dade no primeiro ano de governo e nos primeiros meses de 1952; a rigor, apenas nos últimos meses do SGV, já no ano de 1954, é que se pode detectar a adoção de medidas que lembram mais de perto o hard core do que é apontado como populismo econômico. Mas este é período excepcional, marcado por profunda crise política, e a política econômica o reflete, com o governo procurando assegurar sua base de sustentação sindical e parlamentar através de medidas expansionistas - nada tendo a ver com um padrão de comportamento arraigado. Ao contrário, o desfecho do SGV vai na direção contrária do que propõe o ciclo econômico populista: começa propondo estabilização e é ao seu final que predomina o discurso nacionalista e pró-distribuição.

A partir de meados de 1952, com o aumento da pressão política, o governo cedeu com reajuste do salário mínimo. Também houve expansão da dívida dos estados, municípios e distrito federal: as despesas cresceram em termos reais, o mesmo ocorrendo com as receitas, embora em menor ritmo. $\mathrm{O}$ ano de 1952 fechou invertendo em parte os resultados da política de estabilização: o PIB cresceu 7,3\%, após quatro anos de queda, e a balança comercial apresentou o saldo negativo de US\$286 milhões, o maior desde a Grande Depressão. Entretanto, o orçamento da União continuava com superávit (Tabela 1). Por outro lado, a substituição de Truman pelo republicano Eisenhower na Presidência dos Estados Unidos alterava as relações internacionais: estes abandonam a prioridade aos projetos da Comissão Mista, acenando com a possibilidade de financiamento privado, projeto a projeto, o contrário do que o governo brasileiro entendia como acertado. Os sentimentos nacionalistas se aguçam com a campanha pela nacionalização do petróleo e aumentam as greves, pressionando por novos aumentos de salários, já que a inflação se acelerava. Em janeiro de 1953, o governo implementou medida sugerindo não abrir mão da estabilidade com a edição da Lei do Mercado Livre (Lei 1.807), cujo propósito era atrair capital estrangeiro via liberdade cambial e afrouxamento dos critérios para reinvestimentos. Não obstante, e a mostrar que não abriria mão dos compromissos industrializantes e desenvolvimentistas, mantinha a política de segmentar tanto as importações por faixas de acordo com a essencialidade dos bens, como as exportações em categorias conforme o peso do produto na pauta, de forma a incentivar sua diversificação. Assim, sem eliminar o controle quantitativo das importações, a administração do câmbio começava a ser feita através de desvalorizações cambiais de acordo com as faixas em que os bens eram enquadrados (duas para as importações, cinco para as exportações). Na prática, ficava estabelecido um sistema de taxas múltiplas de câmbio o qual buscava compatibilizar uma saída para a crise do balanço de

do modelo de Barro (1986), mostrou-se que não se tratou de uma "virada" abrupta, mas de um período de randomização de mais de um ano, no qual políticas oscilatórias pró-estabilidade e expansivas se sucederam, como resultado de pressões políticas. 
pagamentos com o crescimento econômico, pois privilegiava a importação de bens de capital e insumos essenciais, administrando ganhos e perdas decorrentes da crise cambial segundo um critério nitidamente político e pró-desenvolvimento.

Mas a mais importante medida desse período foi a Instrução 70 da SUMOC, de outubro de 1953. Esta foi precedida de reforma ministerial na qual Vargas convidou Osvaldo Aranha para substituir Lafer na Fazenda, como a mostrar que seguia um caminho de aproximação com os círculos financeiros nacionais e internacionais e, portanto, avesso a qualquer padrão de populismo econômico. Mas, ao mesmo tempo, empossou João Goulart no Ministério do Trabalho, então presidente nacional do Partido Trabalhista Brasileiro - PTB, com amplo trânsito entre os sindicalistas próximos ao governo (os "pelegos") e o político mais criticado pela oposição conservadora liderada pela União Democrática Nacional - UDN. A Instrução estabeleceu o monopólio cambial ao Banco do Brasil e o sistema de leilões de câmbio em substituição aos licenciamentos. Continuavam cinco faixas para importação, de acordo com a essencialidade, para as quais haveria alocação específica de montantes de divisas a serem leiloadas. Permanecia no papel um dólar oficial fixo $(\mathrm{Cr} \$ 18,50)$, mas na prática este era acrescido de um ágio decorrente do leilão. Para o setor exportador, estipulou-se um bônus sobre o dólar oficial de Cr\$ 5,00 para as exportações de café e de Cr\$10,00 para os demais produtos. A medida mostra que o governo, mesmo tendo cedido nas áreas salarial e fiscal, continuava com a busca da estabilidade no balanço de pagamentos e, no limite, desvaloriza o cruzeiro - comportamento avesso ao populismo econômico, mas perfeitamente conciliável com o projeto desenvolvimentista: se a desvalorização cambial encarecia a curto prazo os bens de capital e os insumos importados e iria se refletir nos bens de consumo com o aumento do preço do dólar em todas as faixas, este recairia sobretudo sobre os bens considerados "menos essenciais", já que cerca de $80 \%$ das divisas leiloadas destinavam-se às três primeiras faixas. Além do mais, a diferença entre o ágio obtido nos leilões e o bônus pago aos exportadores acima do dólar oficial representou na prática um aumento de impostos, pois adicionou nova fonte de receita ao setor público, também contrariando os modelos que assinalam a aversão de governos populistas a medidas deste teor. Como já se mostrou, os modelos — principalmente de Díaz-Alejandro ([1981]1991) e Bresser-Pereira (1989) - ressaem a prática dos mesmos por recair na preferência por cobrir os gastos públicos com emissão monetária e não por medidas como aumento de impostos, sempre impopular ou por ser considerado dispensável, dinate da necessidade de "reformas estruturais".

Apesar dos esforços de Lafer e de Aranha na área cambial, cujas medidas dependeriam de certa defasagem de tempo para apresentar resultados, havia atrasados comerciais e a inflação não cedia. Entretanto, como primeiro sinal, a balança comercial fechou o ano de 1953 com resultado positivo, invertendo 
a tendência e a mostrar que as tentativas de estabilização já antecipavam algum resultado, e o déficit no balanço de pagamentos deu lugar a pequeno superávit (Tabela 1). A maior pressão vinha da política monetária, com o crédito ao Tesouro pelo Banco do Brasil (Vianna, in Abreu, 1989, p. 142). O quadro político agravou-se com a divulgação de um estudo do Ministério do Trabalho, vazado à imprensa, com a proposta para apreciação presidencial de aumento de $100 \%$ para o salário mínimo. Fato inusitado: gradualmente o palco dos acontecimentos da área econômica, para onde normalmente se voltam as atenções, não era mais o Ministério da Fazenda, mas o do Trabalho. O clima de radicalização começava a ganhar proporção nunca vista; sem centro no campo político com capacidade de mediação, a divisão do país em dois blocos antecipava 1964. Em janeiro de 1954 o "Manifesto dos Coronéis" exigia a demissão de Goulart do ministério. Vargas pareceu inicialmente implacável às pressões, mas, no mês seguinte, Goulart deixava o cargo. Tudo parecia sugerir a vitória fora das forças oposicionistas e o movimento sindical voltava a organizar-se possivelmente para nova ofensiva. Todavia, Vargas surpreende e, em $1^{\circ}$ de maio, anuncia oficialmente o aumento de $100 \%$ do salário mínimo e, com ele, verdadeiro "pacote" para a área trabalhista e previdenciária. ${ }^{11}$ Apenas nestes meses finais do SGV, encerrada com seu suicídio em agosto de 1964 e certamente atípica, com o país mergulhado em profunda crise, podem-se visualizar políticas mais próximas do hard core dos modelos de populismo econômico. Talvez a dramaticidade da conjuntura desses poucos meses tenha contribuído para consagrá-los na memória histórica e ajudado a criar o mito do populismo varguista, embora seus poucos meses não permitam generalizá-lo para o conjunto do período governamental.

\section{CONCLUSÃO: O DESENVOLVIMENTISMO SEM POPULISMO}

A análise da política econômica do SGV traz evidências suficientes para dar guarida à hipótese de que esta se afasta do preconizado pelos modelos de ciclo econômico populista. A sucessão de medidas adotadas, inclusive, vai em direção oposta, ferindo um dos principais supostos de todos os autores que se debruçaram sobre o tema, pois começa com políticas de estabilização, implan-

\footnotetext{
${ }^{11} \mathrm{O}$ conjunto de medidas possivelmente seja o último com vistas a ampliar direitos sociais até a Constituinte de 1988: extensão de benefícios previdenciários a várias categorias de trabalhadores e seus dependentes, inclusive profissionais liberais autônomos, domésticas e trabalhadores rurais; extensão, a estes últimos, através da Carteira do Trabalhador Rural, de estabilidade, duração de jornada de trabalho e proteção ao trabalho da mulher e do menor; fim do limite do valor das pensões, tornando-as proporcionais aos salários; aposentadoria aos 55 anos de idade para atividades "penosas e insalubres"; criação do auxílio-matrimônio; e, finalmente, participação dos trabalhadores na gestão dos institutos de aposentadorias e pensões (Fonseca, 1989, p. 450).
} 
tadas pelos governos e reconhecidas, explicitamente, como necessárias. Além disso, a preocupação perdurou nos anos seguintes e abrangeu todas as áreas constantes do hard core dos modelos, pois englobou tanto as políticas salarial, fiscal e cambial (embora nesta nos dois primeiros anos seja menos evidente, devido à taxa fixa de câmbio, cuja adoção respalda-se, em boa medida, no cumprimento do acordo de Bretton Woods. A outra alternativa - rompimento unilateral com este - não seria mais próxima da construção típico-ideal de populismo?). Mesmo que as tenha "flexibilizado" a partir de meados de 1952, nota-se que a preocupação com a estabilização perdurou pelo menos até o final de 1953, com a entrada de Aranha no ministério e a Instrução 70 da SUMOC. Somente a partir de 1954, com a radicalização política, há mudança quanto a esta orientação. Mas esta não só se restringe aos últimos meses de governo como contraria o corolário dos modelos, segundo o qual o populismo econômico teria de evidenciar uma convicção ou padrão de comportamento dos governantes e dos policymakers sobre a condução da política econômica, uma opção, e não ações decorrentes de circunstâncias excepcionais ou de variáveis exógenas. Finalmente, a herança legada pelo $S G V$ também não é a prevista pelos modelos. Enquanto estes preveem recessão e total descontrole, o governo que o sucedeu, mesmo mais afinado com a ortodoxia, com Gudin na pasta da Fazenda, manteve diretrizes como a Instrução 70, colhendo os frutos tanto do ajuste cambial como do fiscal, e pouco tempo depois o Brasil entraria no ciclo expansivo do Plano de Metas.

A análise do período também traz robustez à tese segundo a qual não há uma relação unívoca e indissociável entre desenvolvimentismo e populismo econômico. A adoção de políticas de estabilização não fere o projeto desenvolvimentista, posto que adotadas pelos policymakers com o propósito de evitar que os desequilíbrios macroeconômicos se agucem — e, inclusive, inviabilizem o próprio crescimento. ${ }^{12}$ Parte da literatura, ao assumir tal incompatibilidade como pressuposto (ou seja, verdade a priori que, por sua evidência, dispensaria prova), passou a admitir que as medidas de estabilização de fato ocorreram no SGV - mas procurou então apagar sua outra dimensão: o desenvolvimentismo. Esta interpretação, todavia, fica prejudicada quando se adiciona à aná-

\footnotetext{
12 Problema semelhante ocorreu por ocasião do Governo Goulart, quando coube aos ministros San Thiago Dantas e Celso Furtado a responsabilidade do acompanhamento e execução do Plano Trienal e da política econômica. A acusação de que ambos haviam traído seus ideais ao assumirem o governo foi largamente explorada à época. Furtado, particularmente, respondia mostrando que sem haver um mínimo de estabilidade todos os investimentos e reformas previstos pelo plano ficariam comprometidos. Ou seja: os críticos raciocinavam com um mundo ideal onde não havia restrições orçamentárias e cambiais, como se a questão se restringisse à "vontade política" e pudesse a equipe econômica fugir à responsabilidade de enfrentar a inflação e a crise do balanço de pagamentos, e levar o país à inadimplência. A posição de Furtado deixa claro qual a proposta do nacional-desenvolvimentismo: não é crescer sempre e a qualquer custo; em determinadas conjunturas, diminuir o ritmo do crescimento com vistas à estabilidade é o melhor caminho para preservar o crescimento de longo prazo.
} 
lise a ação do governo como um todo, além das políticas instrumentais de estabilização (monetárias, cambiais, salariais e fiscais).

Destarte, mesmo que a política instrumental incorporasse a estabilidade macroeconômica, não se podem ignorar as mudanças institucionais, de longo prazo, impulsionadas por Vargas desde 1930, cujo sentido em seu conjunto permite vislumbrar um projeto para o país, cujo epicentro era o rompimento com a agroexportação através da industrialização por substituição de importações. Já na década de 1930 o projeto torna-se perceptível com o aparecimento de novas leis, como as do trabalho, da educação (reforma Francisco Campos, com prioridade ao ensino técnico-profissional), a reforma tributária de 1934, os Códigos de Minas e de Águas, ambos também de 1934; novos órgãos voltados a incentivar a produção e regulá-la, como os institutos do Café, do Açúcar e do Álcool, do Pinho, do Mate e da Borracha, dentre outros; para racionalizar o crédito, como a Carteira de Crédito Agrícola e Industrial do Banco do Brasil, de 1937; e, finalmente, com a intervenção direta do governo na produção industrial, com a criação da Companhia Siderúrgica Nacional, com a Usina de Volta Redonda, e com a Companhia Vale do Rio Doce, no início da década de 1940. Não cabe aqui enumerar ad nauseam os órgãos criados no SGV em continuidade a esta política, mas registra-se o fato já mencionado da criação da Assessoria Econômica, uma inovação, já que especializa parte da equipe econômica no planejamento de longo prazo, a antecipar um futuro ministério para a área. ${ }^{13}$ Junto a esta, criaram-se comissões para tratar temas específicos (como de Desenvolvimento Nacional, de Coordenação e Desenvolvimento de Transportes, de Abastecimento e Preços, de Intercâmbio Comercial com o Exterior, e de Revisão de Tarifas Aduaneiras, dentre outras) e para propor planos nacionais (para transportes, como tratores, caminhões e automóveis; para energia, como voltado ao petróleo, à eletrificação e ao carvão). $\mathrm{Na}$ área financeira e do crédito, criaram-se o Banco de Crédito do Amazonas e o Banco do Nordeste do Brasil, além do Banco Nacional de Desenvolvimento Econômico - BNDE. Este, juntamente com a PETROBRAS e a ELETROBRAS, tornar-se-ia um dos órgãos símbolo do nacional-desenvolvimentismo brasileiro. Estas medidas institucionais de vulto, por suposto intencionais e com racionalidade instrumental entre fins e meios, no sentido weberiano, não podem ser entendidas seja como populismo ou, tampouco, como ortodoxia ou conservadorismo. Que ortodoxia é esta que encampa um projeto nacional de desenvolvimento e, pioneiramente, cria empresas estatais na esfera produtiva? Que mesmo diante de grave crise no balanço de pagamentos, posterga ao máximo a desvalorização cambial para evitar rompimento com acor-

\footnotetext{
${ }^{13}$ Para uma lista mais completa desses órgãos, respectivamente na década de 1930/Estado Novo e, posteriormente, no SGV, ver: Fonseca (2003, p. 133-148, p. 1989, p. 366). Sobre a Assessoria Econômica de Vargas, ver Santos (2006).
} 
do internacional e, ao adotá-la, o faz de forma a manter a transferência de renda ao setor industrial, em sintonia ao projeto de substituição de importações? Que assume a necessidade de bancos de desenvolvimento e aprofunda a participação estatal no financiamento da economia? E, sobretudo, no mercado de trabalho, com a legislação trabalhista?

Como se pode constatar, nem a política econômica instrumental de estabilização efetivamente implementada nem, tampouco, as medidas institucionais de mais larga envergadura permitem associar o SGV a populismo econômico. Ao mesmo tempo, ajudam a ilustrar que desenvolvimentismo e responsabilidade fiscal, monetária e cambial não são excludentes, nem a priori nem historicamente.

Tabela 1: Indicadores macroeconômicos do SGV

\begin{tabular}{cccccccc}
\hline Ano & $\begin{array}{c}\text { PIB } \\
\text { (var.\%) }\end{array}$ & $\begin{array}{c}\text { Inflação/ } \\
\text { (var. \%) }\end{array}$ & $\begin{array}{c}\text { Receita da } \\
\text { União* }\end{array}$ & $\begin{array}{c}\text { Despesa } \\
\text { da União* }\end{array}$ & $\begin{array}{c}\text { Déficit. ou } \\
\text { Superávit* }\end{array}$ & $\begin{array}{c}\text { Balança } \\
\text { Comercial }\end{array}$ & $\begin{array}{c}\text { Balanço de } \\
\text { Pagamentos }\end{array}$ \\
\hline 1950 & 6,8 & 12,4 & 19,37 & 23,67 & $-4,30$ & 425 & 52 \\
1951 & 4,9 & 12,3 & 23,17 & 20,78 & 2,38 & 68 & -291 \\
1952 & 7,3 & 12,7 & 23,75 & 21,99 & 1,76 & -286 & -615 \\
1953 & 4,7 & 20,6 & 25,16 & 27,11 & $-1,95$ & 424 & 16 \\
1954 & 7,8 & 25,8 & 24,86 & 26,31 & $-1,45$ & 148 & -203 \\
\hline
\end{tabular}

* IGP-DI. Valores deflacionados pelo deflator implícito do PIB.

** Cr\$ bi de 1950

*** US\$ milhões

Fonte: Estatísticas Históricas do Brasil (IBGE)

\section{REFERÊNCIAS BIBLIOGRÁFICAS}

ABREU, M. P., org. (1989) A Ordem do Progresso; Cem Anos de Política Econômica Republicana 1889-1989. Rio de Janeiro: Campus.

BASTOS, P. P. Z. (2004) "O presidente desiludido: a campanha liberal e o pêndulo de política econômica no governo Dutra (1942-1948)". História Econômica e História das Empresas, 7(1): 99-135.

(2009) "Qual o projeto econômico varguista?”, Texto para Discussão, Campinas: IE/UNICAMP.

BARRO, R. (1986) "Reputation in a model of monetary policy with incomplete information". Journal of Monetary Economics, 17(1): 3-20.

BIELSCHOWSKY, R. (1988) Pensamento Econômico Brasileiro: o Ciclo Ideológico do Desenvolvimentismo. Rio de Janeiro: IPA/INPES.

BODEA, M. (1992) Trabalhismo e Populismo no Rio Grande do Sul, Porto Alegre: UFRGS.

BRESSER-PEREIRA, L. C. ([1968] 2003) Desenvolvimento e crise no Brasil. São Paulo: Ed 34. org. (1991) Populismo Econômico: Ortodoxia, Desenvolvimentismo e Populismo na América Latina. São Paulo: Nobel.

(2004) “O novo desenvolvimentismo”. Folha de S. Paulo, 19.09.2004. 
(2006) “O novo desenvolvimentismo e a ortodoxia convencional”. São Paulo em Perspectiva, 20(1): 5-24.

(2006b) “A Argentina aprendeu”. Folha de S. Paulo, 6.11.2006.

(2007) Macroeconomia da Estagnação. São Paulo, Ed. 34.

BRESSER-PEREIRA, L. C. e NAKANO, Y. (2003) "Crescimento econômico com poupança externa?" Revista de Economia Política, 22(2): 3-27.

BRESSER-PEREIRA, L. C. e GALA, P. (2007) "Por que a poupança externa não promove crescimento". Revista de Economia Política, 25(1): 3-19.

CANITROT, A. ([1975] 1991) “La experiencia populista de distribución de ingresos”, Desarrollo Económico, 15(59): 331-351.

CUNHA, A. e FERRARI, A. (2009) “Argentina: um caso de novo desenvolvimentismo?”, Revista de Economia Política, 29(1): 3-23.

D’ARAÚJO, M. C. (1982) O Segundo Governo Vargas, 1951-1954. Rio de Janeiro: Zahar.

DIAZ-ALEJANDRO, F. C. ([1981] 1991) "Southern cone stabilization programs", in Cline, W. e Weintraub, S., eds. Economic Stabilization in Developing Countries. Washington, D.C.: The Brooking Institution.

DORNBUSCH, R. e EDWARDS, S ([1989] 1991) The Macroeconomics of Populism in Latin America, Chicago: The University of Chicago Press.

(1990) "Macroeconomic populism”, Journal of Development Economics, 32(2): 247-277.

FERRARI, A. (2007) O Peronismo: Um Fenômeno Argentino, Uma Interpretação da Política Econômica Argentina 1946 - 1955, Tese de Doutorado em Economia, Porto Alegre: UFRGS.

FERREIRA, J. (1997) Trabalhadores do Brasil. O imaginário popular. Rio de Janeiro: Ed. Da FGV. , org. (2001) O Populismo e sua História: Debate e Crítica, Rio de Janeiro: Civilização Brasileira.

(2005) O Imaginário Trabalhista, Rio de janeiro: Civilização Brasileira.

FONSECA, P. C. D. (1989) Vargas: o Capitalismo em Construção, São Paulo: Brasiliense.

(2003) "Sobre a intencionalidade da política industrializante no Brasil na década de 1930".

Revista de Economia Política, 23(1):133-148.

(2004) "Gênese e precursores do desenvolvimentismo no Brasil". Pesquisa e Debate, 15(2): 225-256

FONSECA, P. C. D e MONTEIRO, S. M. M. (2005) "Credibilidade e populismo: a política econômica dos governos Vargas e Goulart”. Revista Brasileira de Economia, 59 (2): 215-243.

GOMES, A. ([1988] 2005) A Invenção do Trabalhismo, Rio de Janeiro: FGV/ Ed 3.

IBGE (1987) Estatísticas Históricas do Brasil. v.3. Rio de Janeiro: IBGE.

LESSA, C. e FIORI, J. (1984) "Houve uma política nacional-populista?", XII Encontro nacional de Economia, São Paulo: ANPEC.

MONTEIRO, S. e SILVA. C. (2009) "Populismo no Brasil: uma análise com teoria dos jogos". VIII Congresso Brasileiro de História Econômica. (http:॥www.abphe.org.br)

NAKANO, Y. (2007) "Populismo cambial”, Folha de São Paulo, Caderno Dinheiro, 12.08.07: 12.

O’DONNELL, G. ([1977] 1991) “Estado y alianzas de clase en Argentina, 1956-1976”, Desarrollo Económico, 16(64): 523-554.

PERSSON, P e TABellini, G. (1995) Monetary and Fiscal Policy, Credibility: Cambridge MIT Press.

SACHS, J. D. ([1989] 1991) "Social conflict and populist policies in Latin America". in Brunette, R. e Delaringa, C., eds. Labor Relations and Economic Performance. Londres: MacMillan Press.

SANTOS, R. B. (2006) A Assessoria da Presidência da República: Contribuição para a Interpretação do Segundo Governo Vargas (1951-1954). Dissertação de Mestrado em História Econômica, Campinas: UNICAMP.

SARETTA, F. (2000) Politica Econômica Brasileira. Araraquara: Unesp.

SICSÚ, J., PAULA, L.F. e MICHEL, R. (org.) (2005) Novo Desenvolvimentismo: um Projeto Nacional 
de Crescimento com Equidade Social. Barueri/Rio de Janeiro: Manoele / Fundação Konrad Adenauer.

(2007) "Por que novo-desenvolvimentismo?" Revista de Economia Política, 27(4): 507-524.

SILVA, C. (2008) Populismo no Brasil na Década de 1930: Uma Aplicação à Teoria dos Jogos. Dissertação de Mestrado em Economia, Porto Alegre: UFRGS.

SKIDMORE, T, (1976) Brasil: de Getúlio a Castelo, 5.ed, Rio de Janeiro: Paz e Terra.

VARGAS, G. (1938-1947) A Nova Política do Brasil. Rio de Janeiro: José Olympio. 11 v. (1950) A Política Trabalhista no Brasil. Rio de Janeiro: José Olympio. (1952) O Governo Trabalhista do Brasil, v.1, Rio de Janeiro: José Olympio.

VIANNA, S. B. (1987) A Politica Econômica no Segundo Governo Vargas. Rio de Janeiro: BNDES. 